\title{
VIRTUAL REALITY FOR HISTORICAL ARCHITECTURE
}

\author{
F. Agnello ${ }^{1}$, F. Avella ${ }^{2}$, S. Agnello ${ }^{3}$, \\ ${ }^{1-2}$ Associated Professor at Department of Architecture, University of Palermo, Palermo, Italy, \\ (fabrizio.agnello, fabrizio.avella) @unipa.it \\ ${ }^{3}$ Graduated in Architecture at University of Palermo, agnellostefania@ virgilio.it
}

\section{Commission II}

KEY WORDS: Virtual Reality, 3D surveying, 3D modeling, Real time rendering, Cultural Heritage

\begin{abstract}
:
This article shows a first step in the development of an immersive virtual tour of the Cathedral of Palermo, entering the fields of Digital Cultural Heritage and Edutainment. Its purpose is to help people to gain knowledge about the site, highlighting the complex stratifications that have characterized its history.

The development of the project has been possible thanks to different phases of work: surveys were initially carried out by laser scanning, then assembled and processed to obtain the 3D model of the current state; at the same time, the model of reconstruction was processed in several phases, based on historical, archival and iconographic sources; both models were, later, subject to postprocessing, preparatory to the development of virtual navigation. The tour scenario includes options in order to make it attractive for the player, such as interactive elements, interfaces and animations.
\end{abstract}

\section{INTRODUCTION}

The objective of this research project is the realization of a virtual tour for an interactive visit of the Cathedral of Palermo, which highlights its complex historical stratifications.

The product is part of the Edutainment field with the aim of making the visit of the monument an active and engaging experience for a vast public, integrating it with data and explanations not physically available during the visit itself, thus conveying cultural tourism (Mortara and Catalano, 2018).

The first phase concerned the study of the state of the art, analyzing the best practices developed nationally and internationally, with particular attention to the works already considered references for the heritage recognized by UNESCO as Digital Heritage and to products developed in the field of videogames.

\section{MAIN CASE STUDIES}

The initial phase involved the analytical study of similar products and four macro-categories were identified based on the applied technology.

\section{- Video:}

The Theater of Taormina (IT Lab of CNR);

- Interactive products that use photographic material: Google Art Project (Google), based on interactive photographic images. There are panoramic photos of the museum sites and photos of high-resolution works connected to information systems;

- Interactive virtual tours based on 3D models for museum use:

Rome Reborn (Polytechnic University of Milan, University of California, University of Virginia, Google). This is a navigable digital model, obtained by laser scanning from a physical model made by Italo Gismondi, of the city of Rome in 320 D.C.;

Scrovegni Chapel (ITABC of CNR). The 3D reconstruction allows observing the frescoes according to various criteria (scene description, thematic vision, exegetical analysis) to overcome the perceptive difficulties of the real visit due to the conservation conditions and the distance of the observer;
Virtual Museum of Iraq (CNR). It is possible to access eight non-navigable rooms virtually, whose finds are inspectable and can display textual information, graphics and the 3D model;

\section{- Videogames}

Discovery Tour: Ancient Egypt (Ubisoft). The User can move along pre-established routes to discover 75 possible urban scenarios of Ptolemaic Egypt.

\section{DATA ACQUISITION AND PROCESSING}

The laser scanning survey of the Cathedral started in 2005, when the Department of Representation of the University of Palermo promoted a workshop for the students of the Italian Doctoral School in Survey and Representation Sciences.

The first step addressed the set up and measure of a topographic polygonal that encompassed the cathedral and provided a reference system for the orientation of point clouds.

The laser scanning survey addressed the documentation of specific areas of the Cathedral, usually linked to degree thesis projects in Architecture, aiming at the reconstruction of the layout of the Cathedral at the end of the $18^{\text {th }}$ century, before the the completion of the great transformation project (which is named 'Riforma'), which gave the Cathedral its present layout (Figure 1).

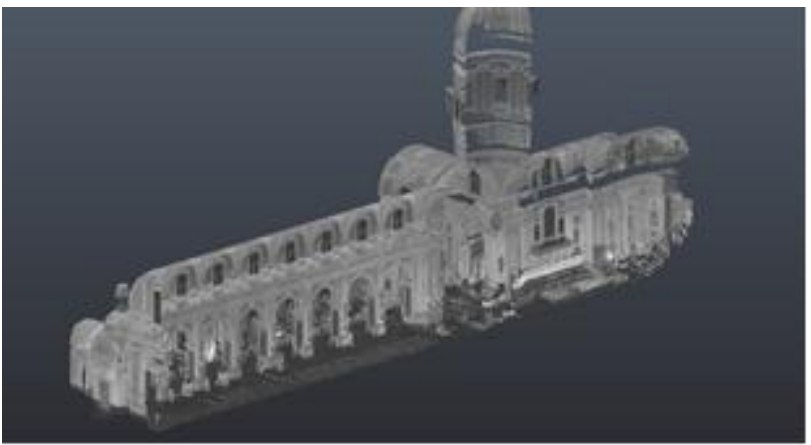

Figure 1: Cloud of point from laser scanning survey. 


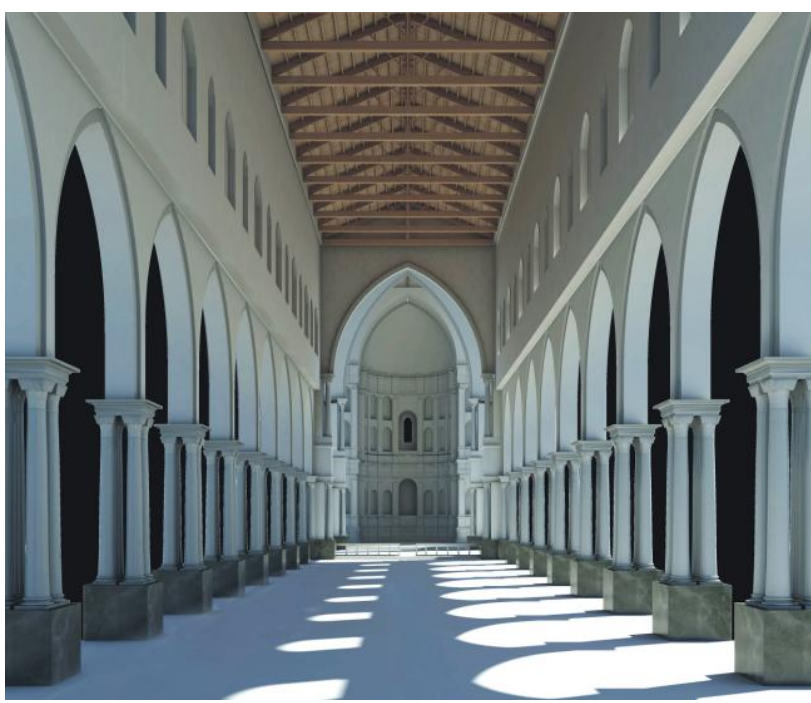

Figure 2: Reconstruction of the nave before the 'Riforma'.
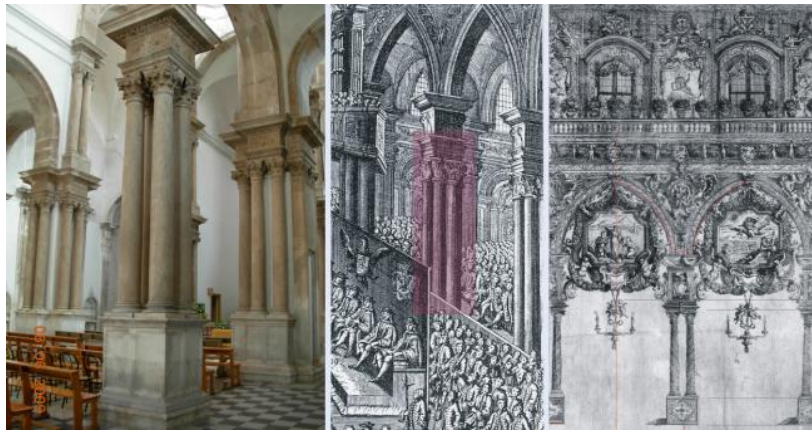

Figure 3: The 'tetra-pillars' in San Giorgio dei Genovesi and two historical drawings displaying the tetra-pillars of the cathedral.

The 'Riforma' deeply changed the spatial layout of the Cathedral; the elements supporting the walls of the nave, made of groups of four columns, were substituted by pillars; the shape of arches changed from pointed to round and the wooden trusses covering the nave were hidden by a barrel vault. The insertion of a huge dome and a transept modified the presbyterial area. The shape of the dome definitely modified the outward character of the Cathedral that originally had a horizontal layout The cathedral before the 'Riforma' preserved the character of the medieval foundation, dating as far back as the XIII century. The additions that were built in the Modern age they did not hid or remove, nor destroy, the architectural elements belonging to the original building. To the contrary, the 'Riforma' deliberately destroyed and hid the traces of the medieval church.

The apses and the southern front are the few elements that survived the 'Riforma'.

The reconstruction of the Cathedral before the 'Riforma', which obviously started from the survey of the survived traces of the cathedral ante-Riforma (Figures 2), was supported by few ancient drawings and by a long and detailed textual description that was published few years before the 'Riforma'. In the book titled 'De Principe temple panormitano' (the most relevant church in Palermo), Francesco Maria Amato provides a detailed description and reports the dimensions of the inner spaces and of many architectural elements.
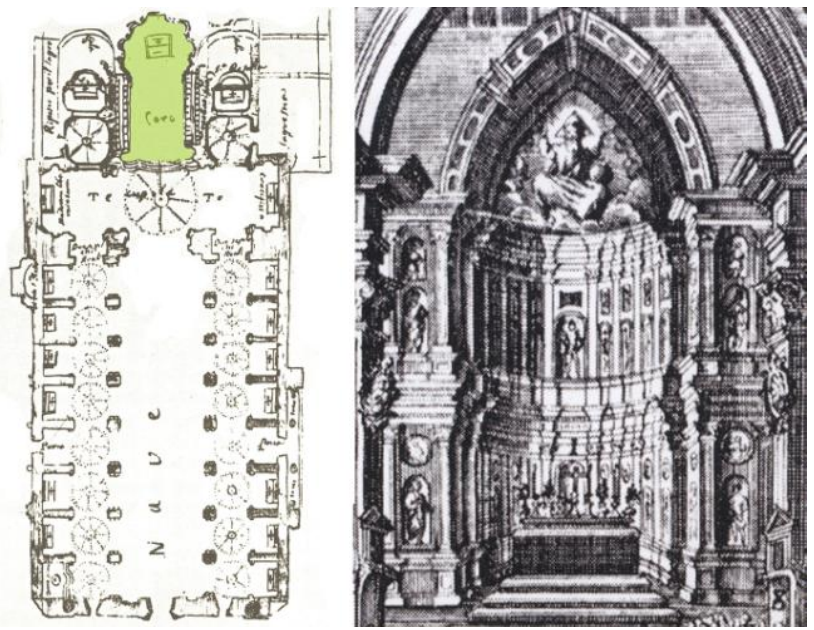

Figure 4: The Tribuna of Gagini.
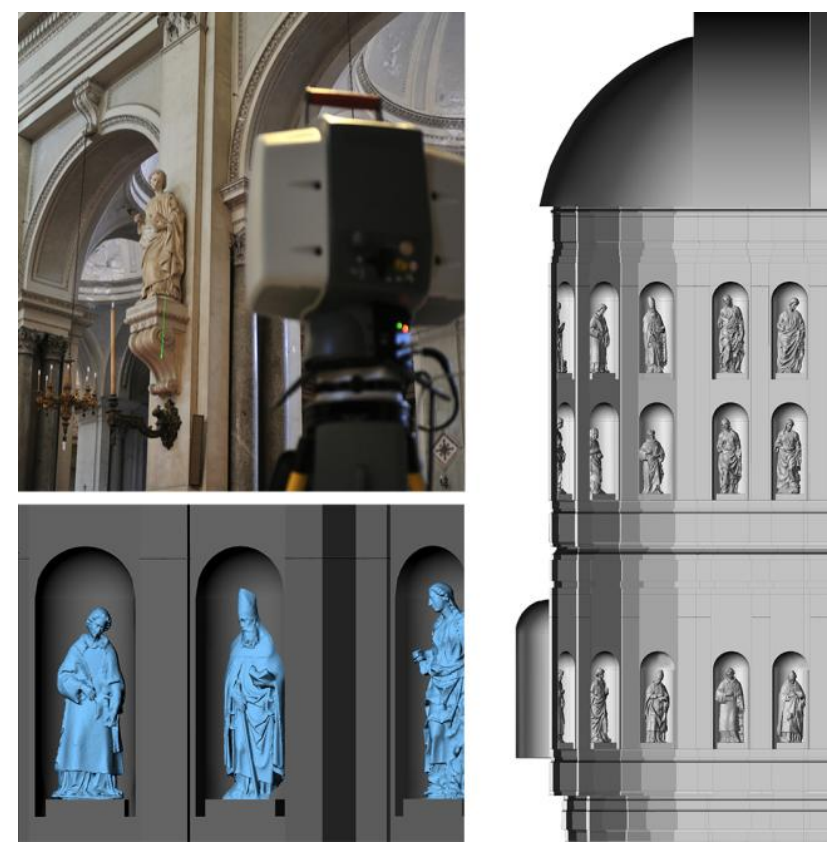

Figure 5: Polygonal model from laser scanning survey of the statues originally placed in the Tribuna.

The first research addressed the reconstruction of the nave, with the groups of 4 columns, therefore named tetra-pillars, bearing the pointed arches (Figure 3). The reconstruction of the pillars was supported by some drawings illustrating the decoration of the nave during a holy day, and by the laser scanning survey of the pillars in San Giorgio dei Genovesi, a church built in Palermo in the XVI century. Historic documents yield evidence that the architect charged for the construction purposely imitated the pillars of the Cathedral.

A later research focused the reconstruction of the 'Tribuna', a huge marble set that was built inside the main apse in the XVI century; the 'Tribuna', which hid the vertical walls of the apse, was made of niches where the statues of saints were located. The 'Riforma' destroyed the 'Tribuna' and the statues are today attached to the pillars of the nave. The reconstruction of the 'Tribuna' was as well supported by drawings and by Amato's textual description (Figures 4-5). 

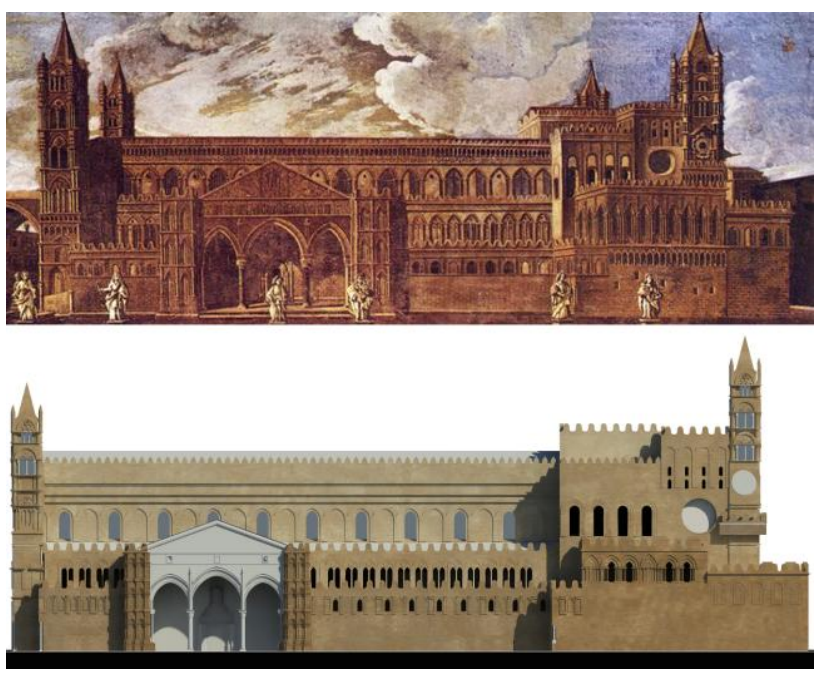

Fig. 6: Reconstruction of the southern front.

A laser scanning survey supported the construction of the 3D polygonal models of the statues, which completed the virtual reconstruction of the 'Tribuna'.

A third research project addressed the reconstruction of the southern front; the sources quoted above proved that the 'Riforma' did not simply insert the dome, but destroyed and rebuilt the southern aisle, shifted outwards the southern wall and built new chapels covered by small domes (Figure 6).

A final research project focused the western wall, which was doubled during the 'Riforma' (Figure 7). The survey and 3D model of the western wall effectively display that the new wall hid the inner face of the original western façade and that some aerial paths cross the gap between the walls. Such paths allowed the maintenance of trusses and provided an escapeway connecting the inside of the church with the archbishop palace, by means of two still extant 'bridge-arches'.

The research resumed in this paper started from the reconstructed 3D models of the nave and of the 'Tribuna' in the main apse. The models have been processed and improved so to make them suit the needs of the real-time rendering application.

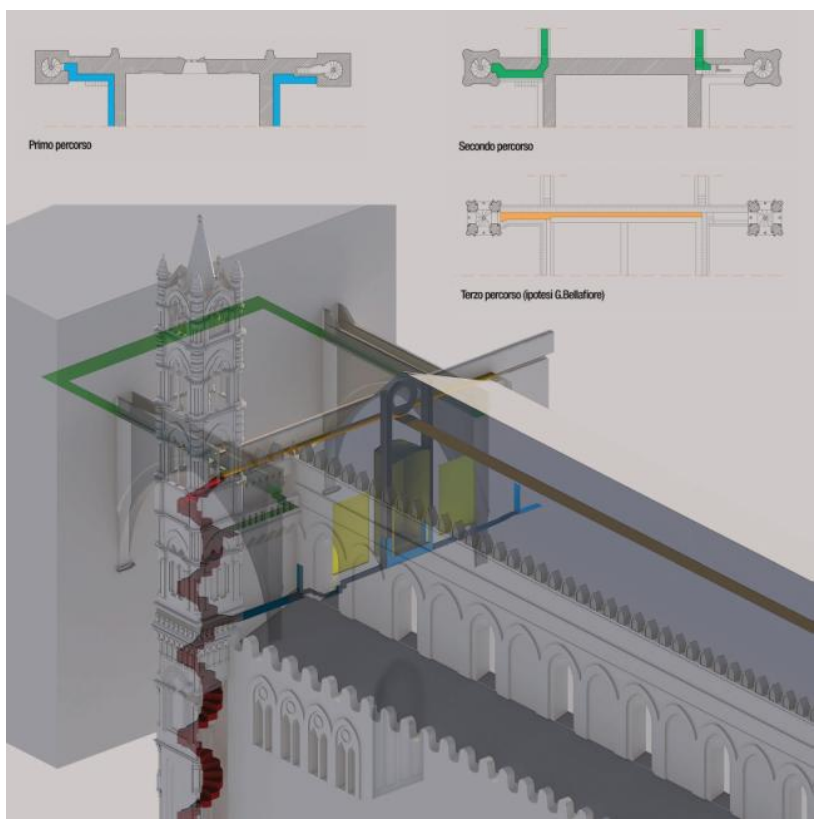

Figure 7: Reconstruction of the western front.

\section{WORKFLOW PHASES}

\subsection{Reconstruction of the environment to be visited}

The partial models of the Cathedral (before the $18^{\text {th }}$ century transformations and in today's layout) and of the Gaginian Tribuna with its statues, have been imported into Autodesk 3DS Max 2017 software (Figures 8).

Subsequently, the geometries were improved (using the tools of selection and modification of the Editable Meshes) and the Attachment of the faces relative to each element was carried out, which allowed the texturing to be achieved in a more appropriate manner. This process involved the use of two different modifiers: $U V W$ Map for UV mapping and Unwrap $U V W$ for the creation of lightmaps.

Later, to avoid the onset of problems in the development of the project within the game engine, additional modifiers were used: Reset Xform and actions on the Hierarchy to conform the orientation of the pivots (by resetting the bounding box of the object to its actual size), and Normal or Flip (depending on whether it was the whole object or part of it) to homogenize the face orientation (i.e. normals' orientation to each face of the elements, to ensure that the assigned textures were visible and not black (Figure 9).

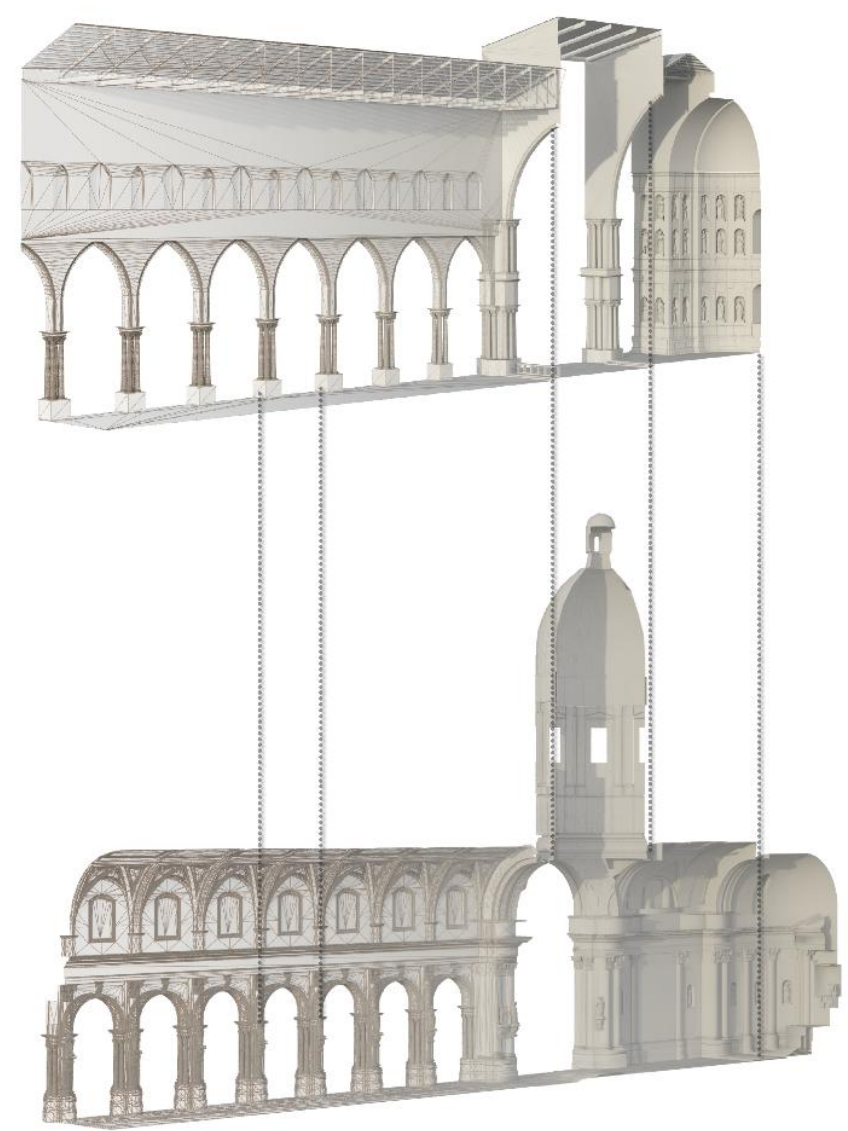


Figure 8: Comparison between the $18^{\text {th }}$ century Cathedral and today's one: wireframe and shaded view of the polygonal model.

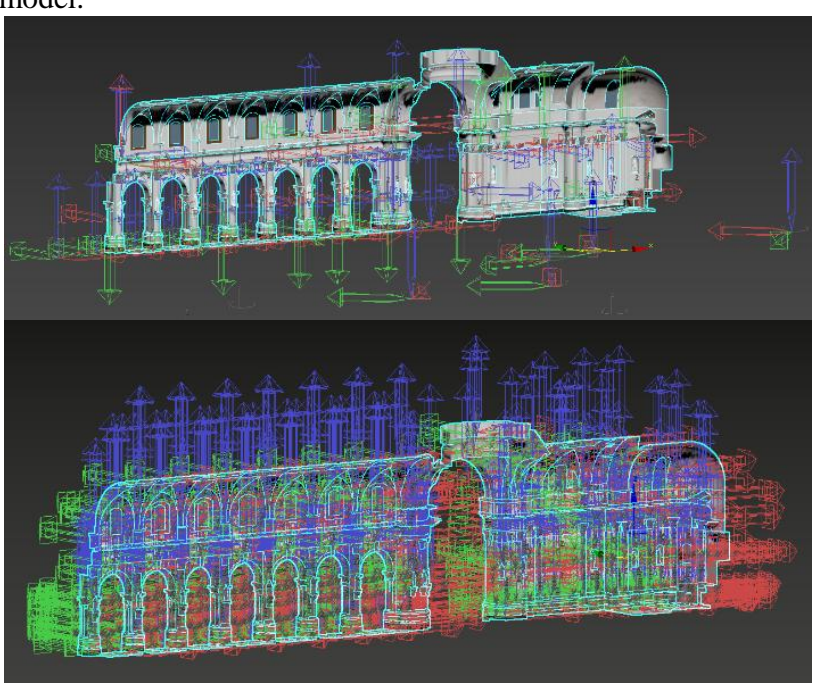

Figure 9: 3DS Max, partial model of the Cathedral before and after the use of the pivot modifier.

Finally, based on specific parameters (such as maintaining objects' curvature and the unit of measure in $\mathrm{cm}$ and storing textures associated with each element), the export from 3DS Max and the import into Unreal Engine were carried out (the same game engine was used in similar case studies: see Basso and Calisi, 2018).

The choice of the game engine was dictated by the fact that this software is widespread internationally for the creation of video games, interactive realities and simulation programs and by the fact that it can publish and export on a large number of platforms. In addition, it integrates physics and collision management components and an audio engine, to develop the project in all aspects using a single program. Inside Unreal, the rendering of scenes characterized by a huge amount of data happens runtime (substantial difference with 3DS's rendering engines) there is a realistic system of lighting and shadow management, the possibility of creating effects through particles (particle system) and the automatic management of computer performances to guarantee fluency (a similar methodology is described in Alamar and Hernandez, 2012).
After the models were imported in Unreal, the collisions were defined (i.e. the properties of completely or specifically

blocking the impacts of the actors in scene, preventing them from walking through the objects) and the environments were reassembled.

The insertion, setting and study of the lights was fundamental. In the case study, a Directional light (simulating sunlight), a Skylight (diffused lighting propagated, even in the real world, from the sky), the Atmospheric fog (a particle system that simulates fog, which allows you to recreate a more realistic lighting) and Sphere reflection capture (native of Unreal, carefully placed on scene to "capture" the surrounding environment and send information to all the reflective materials present) were used. In order to calculate the light in a performing way, specific values were also set in the World settings for the calculation of bounces and exposure, and the entire model was inscribed within two volumes of Unreal's graphic management: the Lightmass Importance Volume and the Post Process Volume.

Respectively, the first one is used to define the spatial limits of the area that needs better definition for global illumination, the second concerns a series of settings on color, white balance, ambient occlusion, depth of field (i.e. most of the corrections that are generally done with photo editing programs), very useful in the finalization phase of the project (about lighting techniques for VR see Anderson, McLoughlin, Liarokapis, Peters, Petridis and De Freitas, 2009).

A particularization of the materials assigned to each architectural element followed, attributing to each one the textures for the diffuse, normal, roughness and ambient occlusion channels such as to determine the characteristics of asperity, transparency and reflection of the material and favour a more realistic perception of the single parts. We opted for the creation of square textures $(1024 \times 1024$ pixels $)$ with the aid of an associated program: Bitmap2Material, which allows, having a basic texture and changing parameters in real time, to export other specific versions of it (Figure 10).

Finally, the Build of the scene was made, that is a construction of the visualization of the environment taking into account both the geometries, materials and lights.

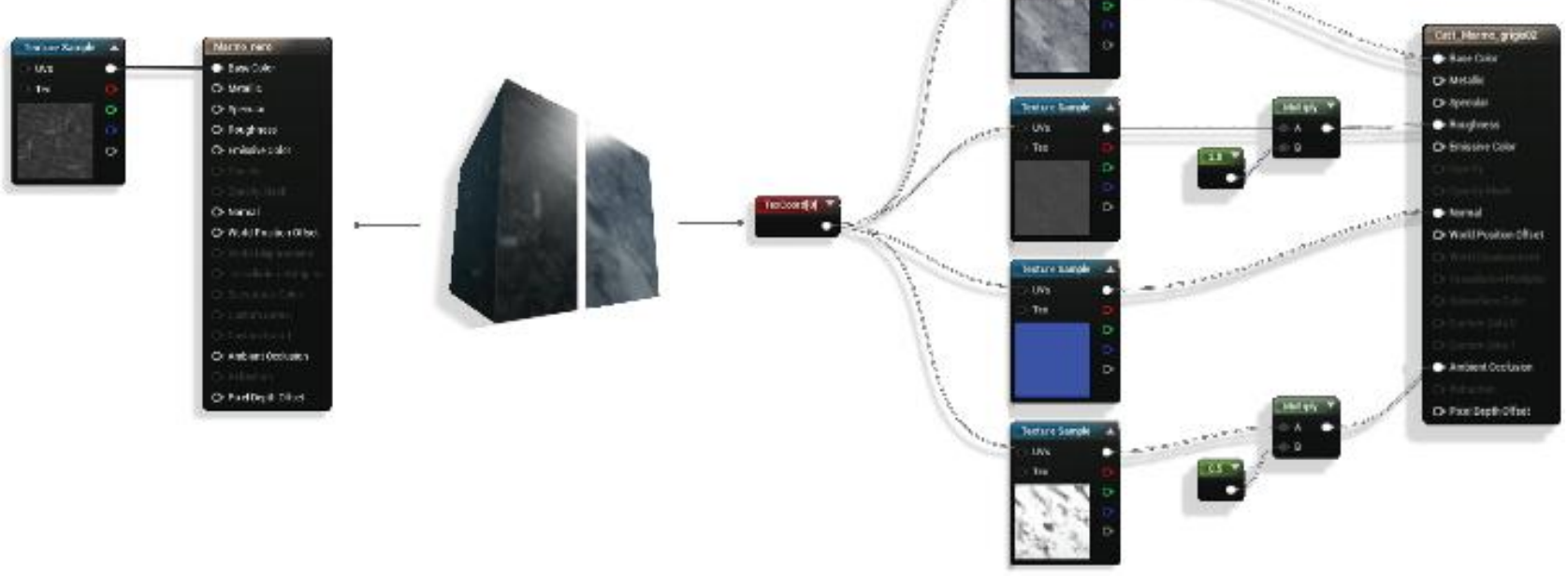

Figure 10: Unreal Engine, a base material and an optimized one. 


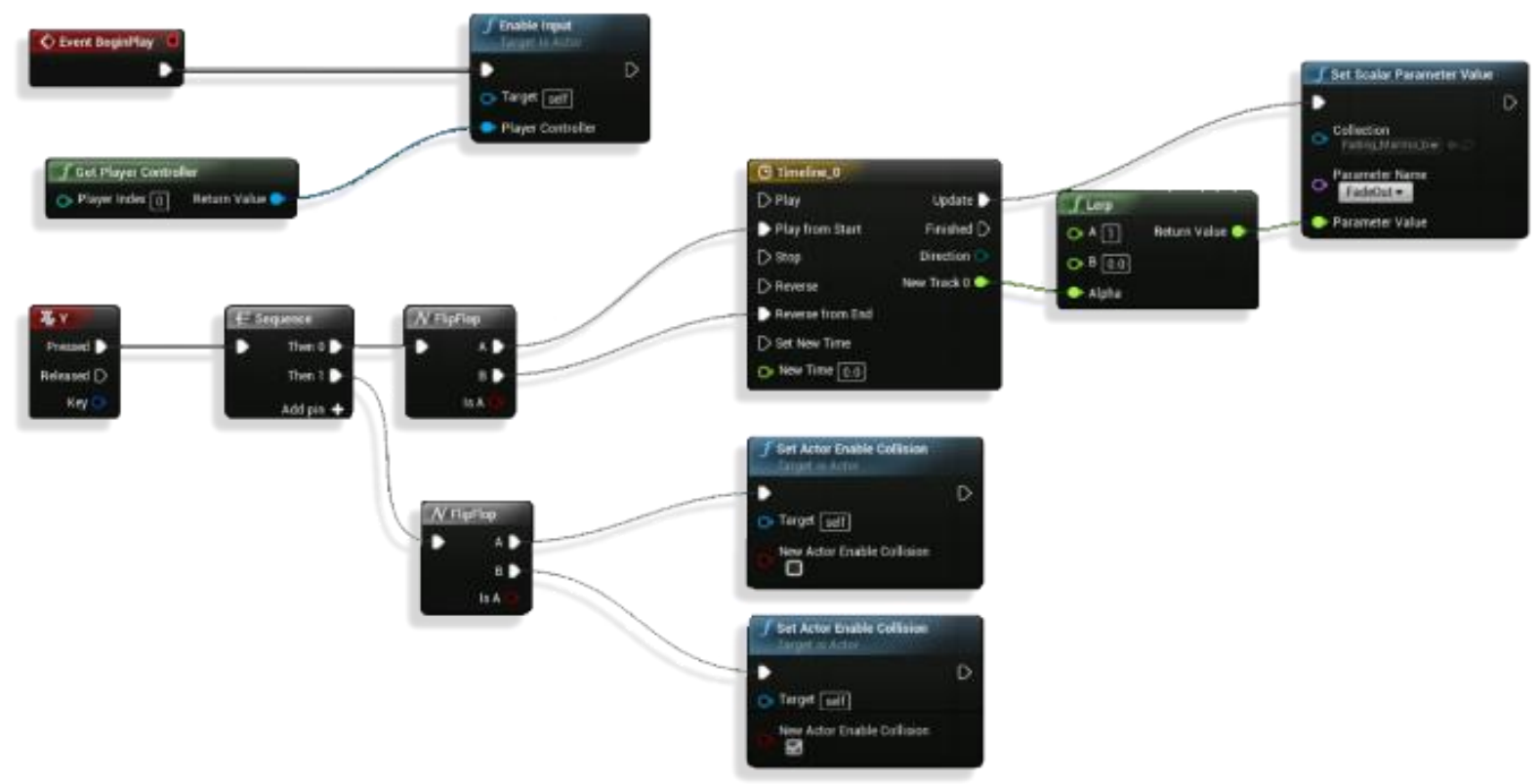

Fig. 11: Blueprint of fading/reappearance of the element.

\subsection{Navigation}

In this specific case, in order to give the User the sensation of actually walking inside the Cathedral, the first person controller was used and suitably modified. In addition, the User will have freedom of movement within the Cathedral, while remaining subject to physical constraints, camera placement (locked so as to maintain the vision always corresponding to the height of the human eye) and the perimeter of the only part analyzed, i.e. the central nave with its apse.

\subsection{Interactive elements}

To set up and control the functions, Unreal's native system of visual scripting was used: the Blueprints. Each blueprint consists of nodes that can receive input, apply operations and functions and send their output to other nodes, creating a complex system of relationships that allows to define the behaviour of objects in the scene in relation to the occurrence of a particular event (such as a mouse click or the pressure of a key on the keyboard).

Through scripting, five interactive elements have been created: 1 - A multimedia totem, with a texture on the screen that shows an indication leading to the web page of the Cathedral, by pressing the $W$ key from the keyboard. You can now explore the website with all the related links, or use a button on the screen to return to navigation.

Visual scripting involved the interaction of a general blueprint (the Level Blueprint, in which the event is set up when the key is pressed) and a widget (that is a graphic component of the User interface, which aims to facilitate the User interaction with the program itself) that allows the loading of the web page or the return to the tour.

2 - A browsable book, which attracts the attention of the virtual visitor by lighting up in proportion to its proximity, accompanied by an indication for its use that appears only if the player (i.e. the User) is within a predetermined volume. This visual scripting has been more complex, because the Level Blueprint (in which the pressure of the $L$ key from the keyboard. has been set) has been connected with an external blueprint that adjusts material's brightness variation, with a second one linked to a trigger volume circumscribed to the book (to make the text appear or disappear) and with a widget in turn programmed to allow to switch from one page to another

3 - The model of the $18^{\text {th }}$ century Cathedral, which has been divided into parts programmed to assemble or deconstruct at the press of a button, appropriately indicated by a text visible in relation to a second trigger volume.

4 - The model of today's Cathedral, also divided into parts programmed to dissolve and reappear simultaneously with the assembly/deconstruction of the $18^{\text {th }}$ century Cathedral, so as not to create totally unrealistic overlaps (Figure 11).

5 - An interface to examine specific elements (Figure 12). This is the most complex of the components inserted, linked to three different blueprints and a widget with relative script for each entity to be analyzed. In general, the blueprints make sure that, by approaching the cursor to the object, it turns into a magnifying glass (to invite the User to deepen) and, clicking on it, opens an interface that shows the name of the element, its textual description and through images and, by blurring the background, allows to rotate the element to be examined until you want to return to the exploration of the environment, by clicking on the closing icon of the interface itself.

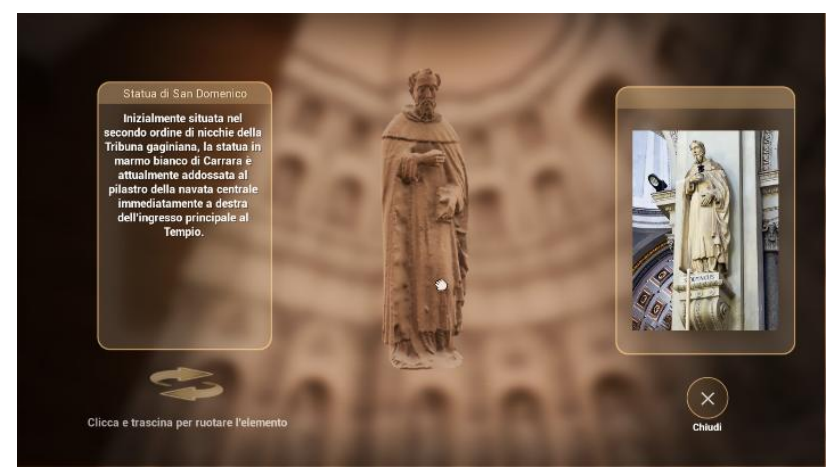

Figure 12: Unreal Engine, analysis interface of the inspectable elements. 


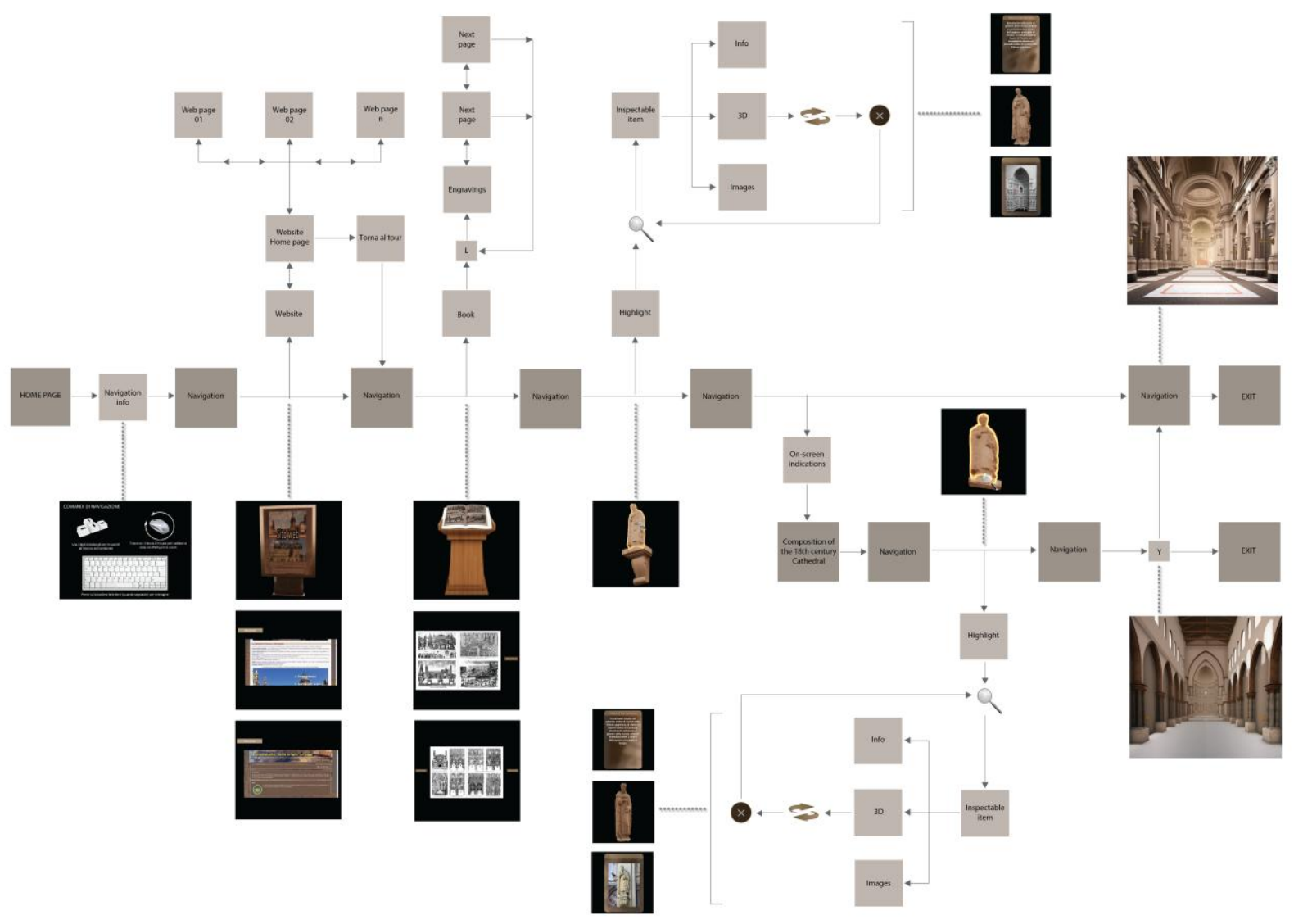

Fig. 13: Taxonomic scheme of actions and User Experience.

\subsection{Optimization}

Although the virtual visit seems to show moving images, what the player actually displays is a sequence of still images. To ensure that no frame rate drops during navigation, it was necessary to optimize the scene.

The optimization has already taken place after the import in unreal, taking care to have meshes with an appropriate amount of polygons, to adapt the resolution of the textures according to the needs of mapping and to position the lights considering that a too high amount of them could weigh down the scene and slow down (if not prevent) the build process. The main tool to lighten the calculation were, however, the Levels of Detail (LODs), based on an algorithm through which it was possible to adjust the number of polygons of the meshes in relation to the distance from the player, making it possible to simplify them (so make them less heavy for the calculation) if placed at a distance, and more and more detailed as the approach takes place, to appreciate the level of detail.

\section{USER EXPERIENCE AND USER INTERFACE}

At present, the project has been developed to be used on PC, and the inputs are currently predisposed for mouse and keyboard.

Navigation is controlled by functions that direct User's actions according to a strict taxonomic scheme that manages primary and secondary actions (Figure 13).

Navigation is free from the beginning and starts from a position near the main entrance, as happens in reality.
The User is then immediately immersed in the perception of the space of the main nave, in its current configuration (Figure 14). The path is not bound to preset tracks and the User can move at will, even if the camera controller blocks it so that he can have the vision corresponding to the real perception, having fixed the height at $1.65 \mathrm{~m}$.

The first interactive elements are clearly visible from the initial screen.

The first is a totem that displays the Cathedral's website, activated by the $W$ key that starts the Create URL Web Browser Widget node, connected to a blueprint widget that manages both the access to the site, and the Torna al tour button, always active, which allows, at any time, to close the web interface and return to navigation.

The second element is a browseable book placed on a lectern, which lights up if the User approaches to stimulate consultation (for the insertion of sensitive areas andaccess keys to interactive panels see Wessels, 2015, Kontogianni and Gergopoulos, 2015). The lighting of the book takes place thanks to two blueprints: the first (called GlowProximity) is a material blueprint that adjusts the brightness of the emissive color, which is activated and increases the intensity in inverse proportion to the distance of the player, thanks to the second blueprint that calculates the Player proximity.

If the User chooses, therefore, to get even closer, driven by interest, when he is inside a trigger volume, invisible to him, he will see the words To start/end the reading of the book, press $L$. Pressing $L$ key opens another widget that activates the Interaction function that gives access to the iconographic material with the possibility of scrolling the pages at will, thanks to the dedicated buttons.

In this phase some $18^{\text {th }}$ century engravings have been inserted that reproduce the Cathedral in various historical moments, with 
particular attention to the $18^{\text {th }}$ century configuration, which will be visible in the virtual tour, but the structure is designed to be expanded and makes possible the inclusion of additional historical and iconographic sources.

If the User decides to end the reading of the book, he can resume the navigation.

When, by rotating the gaze freely, the User frames an element that can be inspected, the cross of the cursor, placed perfectly in the centre of the frame, turn into a magnifying glass and the subject is highlighted with a halo that invites to deepen the knowledge of it.

In the proposed project, the attention was focused on the statues currently placed on the shelves leaning against the pillars of the central nave, originally located in the Tribuna of Gagini, which will later be visible during the navigation of the reconstruction model in their original position.

The activation of the On Examine function node gives access to several variables linked to the inspectable element: the Item name (text variable) shows the name of the displayed object, the Item description (text variable) allows the reading of text descriptions on the object, the Item image displays a raster image. In the case of the statue of San Domenico, for example, the image will show the position of the statue in the Tribuna, which will be visible later during the navigation of the reconstruction model.

The interactive visualization of the 3D model of the object is activated by the Attach to function node that allows to visualize an invisible volume linked to a system of reference axes within which the polygon mesh of the object is placed.

In this way it is possible to rotate the object through the rotation of the pivot connected to it, carried out through the function node Add local rotation.

A dedicated button closes the screen and resumes navigation.

When the player approaches the apse, it crosses another trigger volume, also invisible in this case, which activates the on-screen message To admire the $18^{\text {th }}$ century Cathedral, press $C$. The User can choose whether to ignore the message and continue navigating in the current configuration model or follow the instructions and see the Cathedral model appear in its configuration after 1574 and before 1781 (Figure 15).

The disappearance of the first model and the appearance of the second occur simultaneously, when $C$ key is pressed, but the modes are different and managed by two separate blueprints: the model of the monument in its present state disappears with a fading effect, while the model of reconfiguration appears through vertical translation of the lower part of the colonnade (from below) and the clerestory, the arches of the presbytery and the wooden roof (from above).

The disappearance of the first model concerns the two aspects of visibility and collision, since two sequences belonging to the same blueprint are activated at the same time.

The first sequence, (then 0) manages the fade through the Timeline node that establishes the fade time and is connected to the Set scalar parameter value node; the latter activates the Fadeout parameter, which brings the transparency from its null value to its maximum value of 1 , making the model completely invisible.

Simultaneously, the second sequence (then 1) deactivates the target collision thanks to the Set actor enable collision function node.

The second blueprint activated by the $C$ key triggers the MoveModel event, to which is connected the timeline that regulates the appearance time of the model components.
After identifying the position (function node Get location at distance along spline), the rotation (function node Get rotation at distance along spline) and the length (function node Get spline length), the Move model event forces the translation of the model components in the two opposite directions until they are in the right position.

The User can then continue his navigation inside the model of the $18^{\text {th }}$ Cathedral, until he reaches the apse, where he can see the model of the Tribune of Gagini. Here the User can, again, frame elements that, with the logic and interface described above, will be recognized as inspectable.

In the case of the statue of St. Dominic, for example, you will access a new interface that, in addition to providing written information and giving access to the 3D model, will show a raster image in which, this time, the statue will be displayed in its current location.

It will therefore be possible for the User to relate the positioning of the sculptural element in the $16^{\text {th }}$ century Tribuna to its current location.

Once the navigation of the Tribuna has been completed, the User can decide whether to exit (ESC key) or retrace the central nave, choosing again whether to remain inside the $18^{\text {th }}$ Cathedral or (by pressing the $C$ key) to reappear the current configuration.

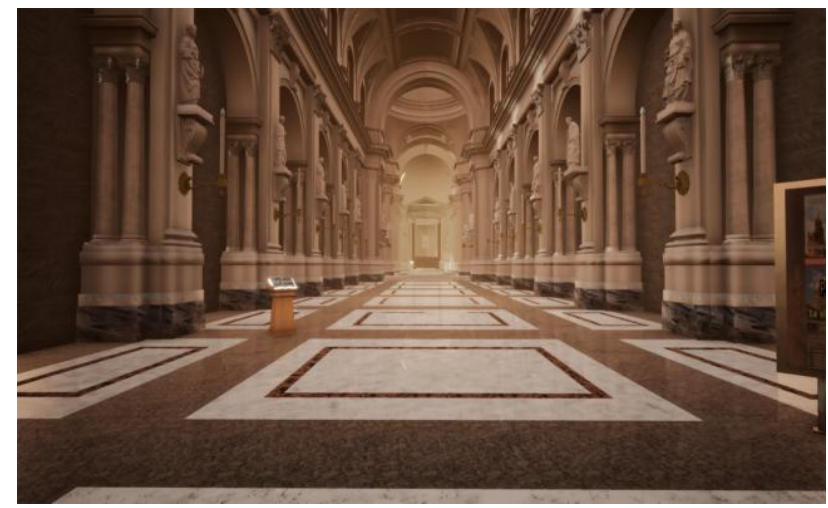

Figure 14: Perspective view of today's Cathedral.

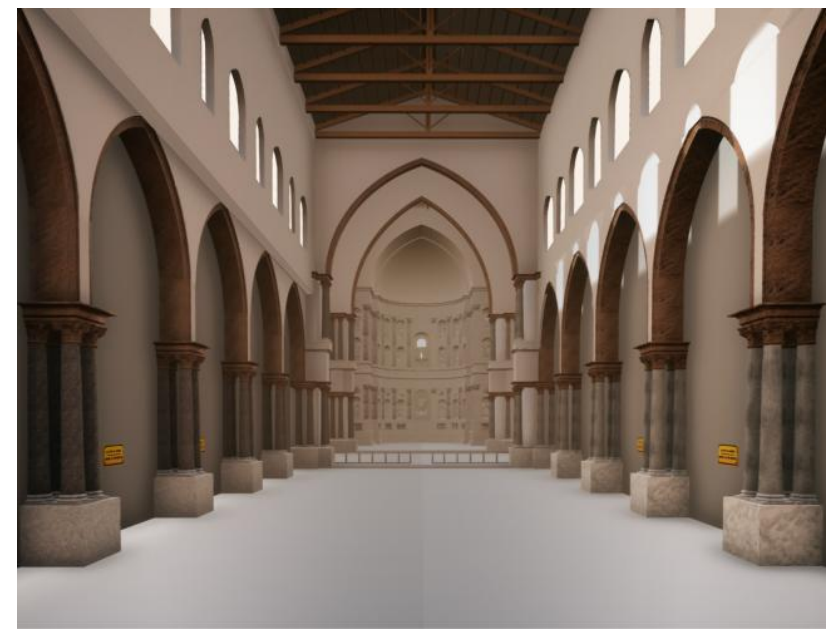

Figure 15: Perspective view of the 18th century Cathedral.

\section{CONCLUSIONS}

The project is carried out according to a notion driven approach, with the aim of enhancing the monumental context, without 
limiting itself to reproducing studies already carried out by traditional means.

The aim is not to replace the real experience, but to integrate it with data and explanations not physically available during the visit, thanks to a multi-channel communication which, unlike the symbolic-reconstructive single-channel communication (characteristic of the written text), is more natural for the human being and improves the understanding, learning and diffusion of knowledge.

Interactive access to the contents of historical research establishes a dialogue with the visitor, whether a tourist or a scholar.

The possibility of online use can also trigger the desire of the real visit.

The future development of the project involves the completion of the navigable model, which also includes the aisles, the complex stratification of the outer shell, the crypt and the Treasury.

The elaborated project, which will be further developed, will be included among the multimedia contents to be made accessible in the Cathedral Museum, in view of a future reconfiguration.

\section{ACKNOWLEDGEMENTS}

The authors would like to acknowledge the scholars mentioned below:

M. R. Nobile and E. Garofalo, for historical research and for the reporting of archival and iconographic material;

Fabrizio Verderosa, for models processed in: La Cattedrale di Palermo prima delle trasformazioni settecentesche. Ricostruzione del prospetto occidentale, dell'angolo sud-ovest e del sistema di percorsi, Degree thesis, a.y. 2009/2010, tutors: F. Agnello and E. Garofalo;

M. R. Virgilio, for his models processed in La Cattedrale di Palermo. La navata meridionale prima delle trasformazioni settecentesche, Degree thesis, a.y. 2009/2010, tutors: F. Agnello and M.R. Nobile;

Clara Lo Franco, for her models processed in La Cattedrale di Palermo prima delle trasformazioni settecentesche: Rilievo e ricostruzione virtuale della zona presbiteriale, Degree thesis, a.y. 2010/2011, tutor: F. Agnello, co-tutors M. Cannella and F. M. Giammusso;

Denise Rinascente, for her models processed in La Cattedrale di Palermo prima delle trasformazioni settecentesche: storia, rilievo e rappresentazio-ne digitale. Degree thesis, a.y. 2008/2009, tutors: F. Agnello and M. R. Nobile;

M. Cannella e F. Giammusso for assistance in the processing of laser surveys and their post-processing.

\section{REFERENCES}

Agnello F., 2013, The Cathedral of Palermo. From survey to historic interpretation. In: Proceedings of the 2013 Digital heritage International Congress, Vol. 1, Track 3, pagg. 713-716.

Alamar, Z. and Hernandez, J., 2012. Reverse Modelling and Virtual Reconstruction Project La Blanca. CHNT - Proceedings of the 17th International Conference on Cultural Heritage and New Technologies.

Amato, G. M., 1728, De Principe Templo panormitano. reprint "Il Tempio dei Re", 2001.

Anderson, E.F., McLoughlin, L., Liarokapis, F., Peters, C., Petridis, P., De Freitas, S., 2009. Serious Games in Cultural Heritage. VAST - Proceedings of the 10th International
Symposium on Virtual Reality, Archaeology and Cultural Heritage.

Basso, A. and Calisi, D., 2018. Acquisition and interactivity of 3D representation connected with the virtual heritage. ReUSO Messina - Proceedings of the 6th international conference on documentation, conservation and recovery of architectural heritage and landscape protection, pp. 2413-2425.

Kontogianni, G. and Georgopoulos, A., 2015. A realistic gamification attempt for the Ancient Agora of Athens. IEEE press.

Mieke PFARR-HARFST, 2012. Research of Digital Cultural Heritage. Virtual Scientific Models. CHNT - Proceedings of the 17th International Conference on Cultural Heritage and New Technologies.

Mortara, M. and Catalano, C. E., 2018. 3D virtual environments as effective learning contexts for cultural heritage. Italian Journal of Educational Technology, 26(2), pp. 5-21.

Wessels, S., 2015. Design and creation of a virtual world of Petra, Jordan. UCT press.

http://itlab.ibam.cnr.it/index.php/teatro-taormina-2017/ https://artsandculture.google.com/ https://www.romereborn.org/content/home-0

http://www.haltadefinizione.com/magnifier.jsp?idopera=15\&pa gina $=1 \#$ multi\&lingua $=$ it

http://www.virtualmuseumiraq.cnr.it

https://support.ubi.com/it-IT/Faqs/000031846/Discovery-Tour-

Mode-of-Assassin-s-Creed-Origins-ACO

(Last accessed on November 2018) 